\title{
Unraveling reduces mobility in a labor market: Gastroenterology with and without a centralized match
}

\section{Citation}

Niederle, Muriel, and Alvin E. Roth. 2003. “Unraveling Reduces Mobility in a Labor Market: Gastroenterology with and Without a Centralized Match." Journal of Political Economy 111 (6) (December): 1342-1352. doi:10.1086/378530.

\section{Published Version}

$10.1086 / 378530$

\section{Permanent link}

http://nrs.harvard.edu/urn-3:HUL.InstRepos:29408444

\section{Terms of Use}

This article was downloaded from Harvard University's DASH repository, and is made available under the terms and conditions applicable to Other Posted Material, as set forth at http:// nrs.harvard.edu/urn-3:HUL.InstRepos:dash.current.terms-of-use\#LAA

\section{Share Your Story}

The Harvard community has made this article openly available.

Please share how this access benefits you. Submit a story.

\section{Accessibility}




\title{
Unraveling Reduces Mobility in a Labor Market: Gastroenterology with and without a Centralized Match
}

\section{Muriel Niederle}

Stanford University

Alvin E. Roth

Harvard University

\begin{abstract}
The entry-level market for American gastroenterologists was organized by a centralized clearinghouse from 1986 to 1996. Before, and since, it has been conducted via a decentralized market in which appointment dates have unraveled to well over a year before the start of employment. We find that, both before and after the years in which the centralized clearinghouse was used, gastroenterologists are less mobile and more likely to be employed at the same hospital in which they were internal medicine residents than when the clearinghouse was in use. This suggests that the clearinghouse not only coordinates the timing of appointments but also increases the scope of the market, compared to a decentralized market with early appointments.
\end{abstract}

\section{Introduction}

In many entry-level labor markets, there have been vigorous efforts to halt the "unraveling" of appointment dates. Unraveling is typically a

An earlier version of this paper was entitled "Input and Output in Gastroenterology." This work was partially supported by a grant from the National Science Foundation. We also thank David Brenner, Fred Gorelick, and Sean Sheehan for agreeing to be interviewed about the demise of the gastroenterology match. Robert Beran, Elliott Peranson, and N. C. Webb helped orient us to the ongoing events in gastroenterology. We thank David Cutler, Ernan Haruvy, and Gerhard Orosel for helpful comments.

[Journal of Political Economy, 2003, vol. 111, no. 6]

(C) 2003 by The University of Chicago. All rights reserved. 0022-3808/2003/11106-0006 $\$ 10.00$ 
dynamic process in which offers are made earlier from year to year. ${ }^{1}$ However, efforts to simply impose uniform appointment dates have most often been unsuccessful.

Some markets have successfully used a centralized clearinghouse to halt the unraveling. There is a good deal of empirical evidence (e.g., Roth 1984, 1991; Roth and Xing 1994) that a key factor in the success of a clearinghouse is whether it produces matches that are stable in the sense that there exist no firm and worker who are not matched to one another but who would both prefer to be matched to one another rather than accept the results of the clearinghouse (cf. Gale and Shapley 1962; Roth and Sotomayor 1990). ${ }^{2}$

To investigate the effect of a centralized clearinghouse on the market it serves, one would want to compare the matchings of applicants to positions when the clearinghouse was in operation to those in the periods both before and after, and so separate the effect of the clearinghouse from other changes in the market over time. Such data are rare, because it is rare for stable clearinghouses to fail. However, as will be described below, gastroenterology had a centralized match from 1986 through 1996 and an unraveled, decentralized market both before and since. (McKinney, Niederle, and Roth [2003] identify gastroenterology as one of only three failures in around a hundred markets organized around a stable clearinghouse.) The availability of data from the gastroenterology market therefore provides us with a unique opportunity.

One effect of a successful clearinghouse is that it halts unraveling and postpones appointments, allowing firms and applicants to have more information about each other's qualities. Roth and Xing (1994) note an additional potential cost of unraveling: as markets unravel, they become thinner, since different firms make offers at different times. By making exploding offers, firms limit the ability of applicants to consider alternative offers (cf. the market for law clerks described in Avery et al. [2001]). In a number of markets, there has been anecdotal evidence that this reduces the scope of the market and forces firms to rely more

\footnotetext{
${ }^{1}$ For example, two markets that are presently experiencing this kind of unraveling are the market for law clerks for federal appellate judges (cf. Avery et al. 2001), in which offers have recently been made almost two years in advance of employment, and the market for college admissions (cf. Avery, Fairbanks, and Zeckhauser 2003), in which elite colleges admit a high percentage of their entering classes through "early decision" programs that require applicants to commit in advance to one college that they will accept its offer if they are admitted early. Roth and Xing (1994) describe several dozen such markets and submarkets. In markets that experience unraveling, applicants typically receive "exploding" offers that must be accepted or rejected before (sometimes any) other offers can be received and considered (see, e.g., Niederle and Roth 2003a).

${ }^{2}$ Many labor markets have features that complicate the definition of stability; see, e.g., Roth and Peranson (1999) for a description of stability in the market for medical residents. The market for gastroenterologists is smaller and simpler than the resident match, and the definition of stability given here is sufficient.
} 
on local applicants. (In Britain, when the market for entry-level medical positions unraveled to over a year before students graduated from medical school, positions at teaching hospitals seemed often to be filled with students from the associated medical school [Roth 1990, 1991]. In Japan, early recruiting is often accomplished through semiformal "old boys" networks, in which graduates from a given university are recruited by former students of that university [Roth and Xing 1994; Rebick 2000].) So a centralized clearinghouse may not only help control market timing but also increase the scope of the market and reduce the need for market participants to rely on informal networks.

An alternative hypothesis is suggested by recent theoretical work by Li and Rosen (1998), Li and Suen (2000), and Suen (2000), who show how unraveling can occur as a form of insurance in competitive markets. In their models, markets clear early but remain competitive, and the scope of the market is not affected by its timing.

One way to assess the impact of the match, and distinguish between these hypotheses, will be to track the scope of the gastroenterology market over time by examining the extent to which gastroenterologists are recruited locally or nationally before, during, and after the match. Because the collapse of the match was sudden, its effect on market outcomes may be particularly visible in the comparison between the match and its aftermath. ${ }^{3}$

A reduction in mobility may also be an indirect indicator of a reduction in efficiency, although here we need to be very careful. A wide view of efficiency in this market would have to include not only the preferences of the market participants-the fellows and their employers-but also the effect that the distribution of fellows to hospitals has on how much the fellows learn and the long-term effect of this on the incidence of gastroenterological diseases. We know of no data that could allow us to measure either the quality of education that fellows receive or the effect this has on the incidence of disease in a way that would allow these issues to be separated from general improvements in health care.

A more narrow view of efficiency would involve only the preferences and welfare of the market participants. In experiments (Kagel and Roth 2000; Haruvy, Roth, and Ünver 2001; McKinney et al. 2003; Niederle and Roth 2003a), unraveling occurs despite the fact that the market participants overall earn less money. In the field data, we have no way to directly observe physician and hospital preferences and, hence, participant welfare. However, if it is efficient for the market to operate more locally, this is something that we would expect to have occurred

\footnotetext{
${ }^{3}$ There is reason to believe that the effects of a match follow only gradually on its initial introduction to a market (see Kagel and Roth 2000; McKinney et al. 2003).
} 
during the match, since a stable match is an efficient outcome. Consequently, when we observe that matching becomes more national in scope during the match and becomes increasingly local after the demise of the match, this is suggestive of efficiency losses as well.

\section{The Gastroenterology Market}

Gastroenterology is a subspecialty of internal medicine. A typical gastroenterology fellow will have previously been employed for three years following medical school as a resident in internal medicine (qualifying to be a board-certified specialist in internal medicine) and then started a gastroenterology fellowship, at the end of which he will be eligible to be a board-certified subspecialist.

The history of the market for gastroenterology fellowship positions is similar to that of many medical markets and submarkets (Roth 1984; Roth and Xing 1994). Before 1985, it suffered from the unraveling of appointment dates, and a number of solutions were attempted prior to the adoption of a centralized match. In 1986 the Medical Specialties Matching Program (MSMP) was initiated by the National Resident Matching Program (NRMP) as part of the Specialties Matching Services. Starting in 1989, the match was conducted for gastroenterology, cardiovascular disease, and pulmonary disease, and since 1994 also for infectious disease (all these are subspecialties of internal medicine). The objective was to establish a uniform appointment date for internal medicine fellowship positions and permit applicants to complete at least two years of their residency before making a decision as to which subspecialty to pursue. The fellowship clearinghouse was conducted a year in advance, that is, after two years of internal medicine residency and one year before employment would begin (National Resident Matching Program 1999).

In such a clearinghouse, applicants and fellowship programs submit rank order lists over positions and applicants, respectively. Then the lists are processed to produce a stable match.

However, from 1997 to 1999 the centralized match suffered from defections, broke down, and was abandoned. The demise of the match can be clearly seen in the number of positions filled through the match each year: While in 1996 around 300 positions participated in the match, by 1999 there were only 14, and in 2000 no centralized match for gastroenterologists was even attempted.

The demise of the match seems to have been set in motion in 1993-94, when, in the midst of general discussions of health care reform, the subspecialty of gastroenterology subjected itself to a manpower analysis published by Meyer et al. (1996). Its main conclusions were that the U.S. health care system and gastroenterologists would benefit from a 
reduction in gastroenterology fellowship programs. The Gastroenterology Leadership Council endorsed a goal of a 25-50 percent reduction in the number of gastroenterology fellows over five years. Furthermore, an additional year of training was mandated: starting in the summer of 1996, three years of training were required to be board eligible instead of two.

However, this announced reduction in supply triggered an even larger reduction in the number of residents who applied for gastroenterology fellowship positions. This seems to have been the start of the demise of the match.

Table 1 shows for each year in which the match took place (one year before the fellowship starts) the number of positions and the number of applicants who participated.

In 1996, for the first time there were fewer applicants for gastroenterology fellowship positions than there were positions offered in the match. This seems to have triggered a scramble among fellowship programs to hire early, before the match. ${ }^{4}$

The year 1997 was the first time a large percentage of positions withdrew from the match and programs moved early to fill their positions with qualified applicants. We shall view 1997 as the first year in which the market was no longer effectively organized via the match. (That is, gastroenterology fellows who began employment in 1998 and hence finished in 2001 will have obtained their job after the match had started to break down. $)^{5}$

Once the match broke down and the commitment to uniform late appointment dates vanished, the market for gastroenterology fellows once again experienced unraveling and exploding offers (e.g., Bauer et al. 1999).

The market also experiences some of the other "typical" costs associated with unraveling, apart from mismatching. The first is that when the time comes to begin employment, some applicants fail to fulfill their obligation, made two years in advance, to join the program whose offer they have accepted. Second, internal medicine residents may not want to consider gastroenterology because they are not willing to commit to a subspecialty this early. Interviews now take place before they have the opportunity to explore other subspecialties (Gorelick 1999).

\footnotetext{
${ }^{4}$ For a detailed account of the collapse of the gastroenterology match and why failures of stable matches are rare, see McKinney et al. (2003).

${ }^{5}$ The parent organization of the match, the NRMP, also changed its policy in reaction to the breakdown of the gastroenterology match. Effective July 1, 2001, the NRMP requires the sponsoring organization to sign an "NRMP Program Directors Annual Participation Agreement" annually committing active participation of at least 75 percent of the eligible programs and a minimum of 75 percent of all available positions in the specialty for a given year. Subsequent failure to register 75 percent of programs or positions in a given year jeopardizes the NRMP's management of future matches.
} 
TABLE 1

Participation in the Gastroenterology Match

\begin{tabular}{|c|c|c|c|c|c|c|c|c|}
\hline Year & $\begin{array}{c}\text { Positions } \\
\text { Advertised }\end{array}$ & $\begin{array}{c}\text { Posts } \\
\text { Withdrawn }\end{array}$ & $\begin{array}{l}\text { Percentage } \\
\text { Withdrawn }\end{array}$ & $\begin{array}{c}\text { Posts in } \\
\text { Match }\end{array}$ & $\begin{array}{c}\text { Percentage } \\
\text { Matched }\end{array}$ & $\begin{array}{c}\text { Number of } \\
\text { Programs }\end{array}$ & $\begin{array}{l}\text { Number of } \\
\text { Applicants }\end{array}$ & $\begin{array}{c}\text { Number of } \\
\text { Applicants/ } \\
\text { Positions } \\
\text { in Match }\end{array}$ \\
\hline 1992 & & $\ldots$ & & 377 & 96.6 & 160 & 658 & 1.75 \\
\hline 1993 & 374 & -25 & -6.7 & 399 & 94 & 173 & 642 & 1.6 \\
\hline 1994 & & $\ldots$ & $\ldots$ & 369 & 93 & 169 & 591 & 1.6 \\
\hline 1995 & 351 & 14 & 4 & 337 & 88.7 & 171 & 433 & 1.3 \\
\hline 1996 & 313 & 15 & 4.8 & 298 & 74.8 & 164 & 277 & .9 \\
\hline 1997 & 254 & 41 & 16.1 & 213 & 85 & 128 & 240 & 1.1 \\
\hline 1998 & 178 & 79 & 44.3 & 99 & 77.8 & 60 & 148 & 1.5 \\
\hline 1999 & 35 & 21 & 60 & 14 & $\ldots$ & 11 & $\ldots$ & $\ldots$ \\
\hline
\end{tabular}

NoTE. - For each year, positions advertised is the number of positions whose availability in the match was announced in late March. Until late May, the programs may add o withdraw positions (posts withdrawn), which leaves the final number of positions in the match (posts in match). Percentage matched is the percentage of positions in the match that are filled by the mach. Nunber of applicants is the total number of applicants who listed at least one gastroenterology program in their 


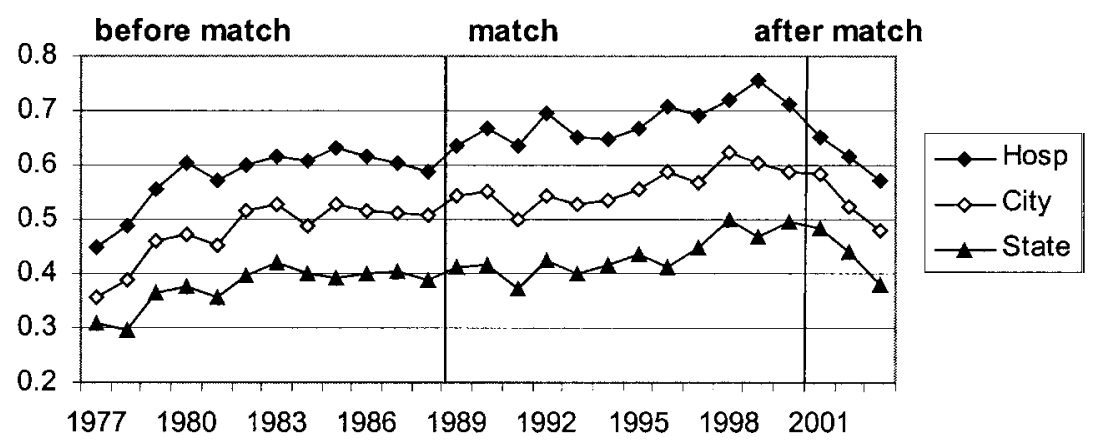

Fig. 1.-Share of mobility of gastroenterology fellows for each year. The vertical lines indicate the beginning and the end of the use of the centralized match, measured in year of fellowship completion.

\section{Mobility of Gastroenterologists with and without a Match}

We purchased from the American Medical Association (via Medical Marketing Service) a data set of all living physicians who have completed, or are currently completing, a gastroenterology fellowship, are boardcertified gastroenterologists, or claim gastroenterology as a specialty. The data contain the years in which each physician graduated from medical school and finished each residency; the specialty of the residency; and the name, city, and state of the institutions at which the medical studies and residencies were done.

Of the 15,187 entries, 9,180 fellows completed a residency in the United States and subsequently a gastroenterology fellowship in the United States after 1977, in 433 different hospital codes coming from 680 places. After 1977, each year (apart from 2003, the last data point) has at least 200 fellows finishing their residency; the numbers are lower before that. ${ }^{6}$

These data allow us to measure changes in the scope of the market by comparing the mobility of gastroenterology fellows when there was a match to the mobility before and after the match. A gastroenterology fellow moves whenever the fellowship is at a hospital different from the residency hospital before the fellowship.

In figure 1, the mobility over hospitals (Hosp) is the percentage of gastroenterology fellows who change hospital after finishing their (mostly) internal medicine residency and starting the gastroenterology fellowship. The mobility over city and state measures the percentage of fellows who move to a different city and state, respectively.

Table 2 provides the differences across mobility with $p$-values, where

${ }^{6}$ For a more detailed account, see Niederle and Roth (2001). 
TABLE 2

DIFFERENCES ACROSS MOBILITY

\begin{tabular}{|c|c|c|c|c|c|c|}
\hline & \multicolumn{6}{|c|}{ DIFFERENCE } \\
\hline & $\begin{array}{l}\text { Match - } \\
\text { Prematch }\end{array}$ & $\begin{array}{l}\text { Match } 1- \\
\text { Prematch }\end{array}$ & $\begin{array}{c}\text { Match } 2- \\
\text { Match } 1\end{array}$ & $\begin{array}{c}\text { Postmatch - } \\
\text { Match } 2\end{array}$ & $\begin{array}{c}\text { Postmatch - } \\
\text { Match }\end{array}$ & $\begin{array}{c}\text { Postmatch } \\
\text { Prematch }\end{array}$ \\
\hline Hospital & $\begin{array}{l}.079 \\
(.0001)\end{array}$ & $\begin{array}{l}.052 \\
(.0015)\end{array}$ & $\begin{array}{l}.053 \\
(.0163)\end{array}$ & $\begin{array}{c}-.096 \\
(.0201)\end{array}$ & $\begin{array}{c}-.069 \\
(.0433)\end{array}$ & $\begin{array}{l}.009 \\
(.5175)\end{array}$ \\
\hline City & $\begin{array}{l}.059 \\
(.0008)\end{array}$ & $\begin{array}{l}.032 \\
(.0184)\end{array}$ & $\begin{array}{l}.054 \\
(.0039)\end{array}$ & $\begin{array}{l}-.058 \\
(.0707)\end{array}$ & $\begin{array}{c}-.031 \\
(.1939)\end{array}$ & $\begin{array}{l}.028 \\
(.4054)\end{array}$ \\
\hline State & $\begin{array}{l}.041 \\
(.0045)\end{array}$ & $\begin{array}{l}.014 \\
(.0990)\end{array}$ & $\begin{array}{l}.053 \\
(.0250)\end{array}$ & $\begin{array}{l}-.026 \\
(.4386)\end{array}$ & $\begin{array}{l}0 \\
(.8852)\end{array}$ & $\begin{array}{l}.041 \\
(.2294)\end{array}$ \\
\hline
\end{tabular}

we use a two-sided Mann-Whitney $U$ test, with the proportion of mobility in each year as our data points.

The introduction of a centralized clearinghouse significantly increases mobility across hospitals, across cities, and across states. That this increase is gradual as measured over the first and second six-year periods of the match conforms with experimental results (Kagel and Roth 2000; McKinney et al. 2003) in which the centralized match only gradually becomes fully used by participants. Mobility sharply declines after the demise of the match, which lends strong support to the hypothesis that the increase in mobility during match years is indeed due to the match, and not to a general change in mobility of physicians over time. This suggests that the centralized clearinghouse has an important effect on the matching of fellows to fellowships, and not only on its timing.

An alternative explanation for the increase in mobility during the use of a centralized clearinghouse may be that different internal medicine physicians, specifically physicians who have always been more mobile, choose to become gastroenterologists. To control for this possibility, we now compute for each gastroenterology fellow a measure of mobility that corresponds to a change in city or state after finishing medical school and moving to the residency completed just before entering their fellowship. For this purpose we discard all foreign graduate students, reducing the sample to 6,789 physicians.

Figure 2 compares mobility from medical school to residency (the "City IM" line) and from residency to gastroenterology fellowship (the "City GI" line) at the city level. (The graph for the state level is very similar. Students always move at the institutional level since they are not employed by the medical schools.) To keep track of the same individuals, they are always tabulated in the year of completion of the gastroenterology fellowship.

Not surprisingly, physicians become less mobile as they advance in their careers. There is no evidence that the change in mobility of gas- 


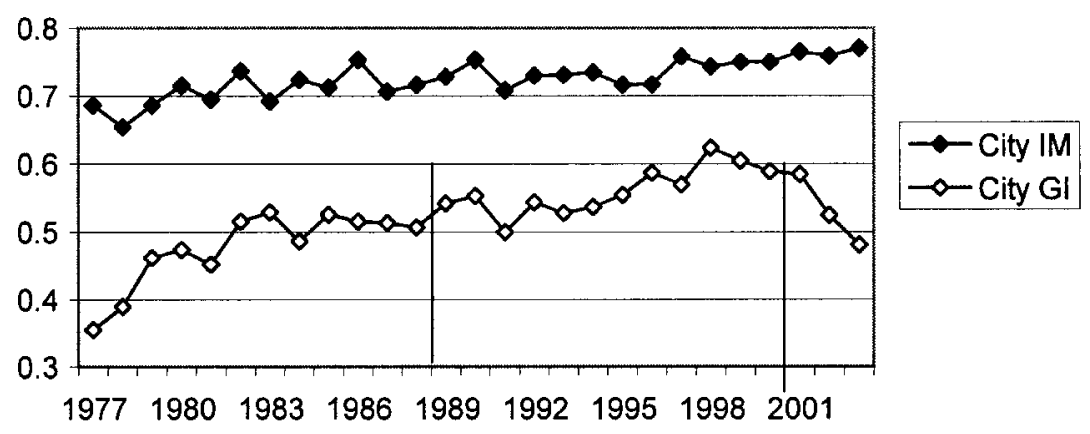

FIG. 2.-Mobility across cities for the fellowship position before gastroenterology (internal medicine) and to gastroenterology. The City GI line represents mobility across cities from residency to gastroenterology fellowship (as in fig. 1); City IM reflects, for the same fellows, mobility between medical school and the last fellowship before gastroenterology (mostly internal medicine). The vertical lines represent the beginning and the end of the match.

troenterology fellows during the centralized match is driven by an increase in mobile physicians choosing to become gastroenterologists. On the contrary, the mobility of fellows between medical school and their fellowship before gastroenterology is slightly increasing over time. That is, even though there is a striking decline in the mobility of gastroenterology fellows before and after the match, when the same individuals were younger and entering their internal medicine residencies, they showed no difference in mobility. ${ }^{7}$

\section{Conclusions}

The data show that the use of a centralized clearinghouse affects not only the timing of the market but also its scope. When the market is decentralized and appointments are made far in advance, the market is less national in scope than when a centralized match was in place. The mobility of gastroenterology fellows, as measured by whether their gastroenterology fellowship is in the same hospital, city, or state as their former residency, significantly increased with the use of a centralized match. ${ }^{8}$

${ }^{7}$ This also makes clear why studying gastroenterologists, for whom we have data not only before the institution of a centralized match but also after its demise, allows us to separate changes in mobility due to changes over time (such as we see in mobility to internal medicine residencies) from changes in mobility due to the market mechanism.

${ }^{8}$ When matching is decentralized and early, hiring seems to occur more through personal networks. Networks can be sources of otherwise scarce information, they can facilitate transactions when they must be completed quickly, and they can enhance the credibility of commitments made years in advance. There appears to have been no effect, however, on wages. Niederle and Roth (2003b) observe that fellowship wages in internal medicine subspecialties that continue to use the MSMP program are not different from fellowship wages in gastroenterology and other subspecialties that do not presently use a match. 
The proximate cause of the demise of the gastroenterology match seems to have been the shock to the market in 1996 (see McKinney et al. [2003] for an experiment that studies such shocks). Since then, the number of positions has stabilized, raising the question of whether a match could be successfully reinstituted. The results of the present study suggest that reintroducing a centralized match would increase the scope of the market and the mobility of gastroenterologists, as well as allow matches to be made after more information has become available.

\section{References}

Avery, Christopher N.; Fairbanks, Andrew; and Zeckhauser, Richard. The Early Admissions Game: Joining the Elite. Cambridge, Mass.: Harvard Univ. Press, 2003.

Avery, Christopher N.; Jolls, Christine; Posner, Richard A.; and Roth, Alvin E. "The Market for Federal Judicial Law Clerks." Univ. Chicago Law Rev. 68 (Summer 2001): 793-902.

Bauer, William T., et al. "Correspondence: It's Time to Bring the Best and Brightest Back to Gastroenterology.” Gastroenterology 116 (April 1999): 1014.

Gale, David, and Shapley, Lloyd. "College Admissions and the Stability of Marriage.” American Math. Monthly 69 (January 1962): 9-15.

Gorelick, Fred S. "Comment from the Editors: Striking Up the Match." Gastroenterology 117 (August 1999): 295.

Haruvy, Ernan; Roth, Alvin E.; and Ünver, M. Utku. "The Dynamics of Law Clerk Matching: An Experimental and Computational Investigation of Proposals for Reform of the Market." Working paper. Cambridge, Mass.: Harvard Univ., Dept. Econ., October 2001. http:/ / papers.ssrn.com.

Kagel, John H., and Roth, Alvin E. "The Dynamics of Reorganization in Matching Markets: A Laboratory Experiment Motivated by a Natural Experiment." Q.J.E. 115 (February 2000): 201-35.

Li, Hao, and Rosen, Sherwin. "Unraveling in Matching Markets." A.E.R. 88 (June 1998): 371-87.

$\mathrm{Li}$, Hao, and Suen, Wing. "Risk Sharing, Sorting, and Early Contracting." J.P.E. 108 (October 2000): 1058-91.

McKinney, Nicholas; Niederle, Muriel; and Roth, Alvin E. "Lessons from the Collapse of a Medical Labor Market." Working paper. Stanford, Calif.: Stanford Univ., 2003. http://www.stanford.edu/ niederle/gastro.experiment.pdf.

Meyer, Gregg S., et al. "Gastroenterology Workforce Modeling." J. American Medical Assoc. 276 (September 4, 1996): 689-94.

National Resident Matching Program. Specialties Matching Services. MSMPData, 1999 Appointments. Washington: Nat. Resident Matching Program, 1999.

Niederle, Muriel, and Roth, Alvin E. "Unraveling Reduces the Scope of an Entry Level Labor Market: Gastroenterology with and without a Centralized Match." Working Paper no. 8616. Cambridge, Mass.: NBER, December 2001.

. "Market Culture: How Norms Governing Exploding Offers Affect Market Performance." Working paper. Stanford, Calif.: Stanford Univ., 2003. (a) http:/ /www.stanford.edu/ niederle/marketculture.pdf.

. "Relationship between Wages and Presence of a Match in Medical Fellowships.” J. American Medical Assoc. 290 (September 3, 2003): 1153-54. (b)

Rebick, Marcus E. "The Importance of Networks in the Market for University 
Graduates in Japan: A Longitudinal Analysis of Hiring Patterns.” Oxford Econ. Papers 52 (July 2000): 471-96.

Roth, Alvin E. "The Evolution of the Labor Market for Medical Interns and Residents: A Case Study in Game Theory.” J.P.E. 92 (December 1984): 9911016.

. "New Physicians: A Natural Experiment in Market Organization.” Science 250 (December 14, 1990): 1524-28.

. "A Natural Experiment in the Organization of Entry-Level Labor Markets: Regional Markets for New Physicians and Surgeons in the United Kingdom." A.E.R. 81 (June 1991): 415-40.

Roth, Alvin E., and Peranson, Elliott. "The Redesign of the Matching Market for American Physicians: Some Engineering Aspects of Economic Design.” A.E.R. 89 (September 1999): 748-80.

Roth, Alvin E., and Sotomayor, Marilda A. Oliveira. Two-Sided Matching: A Study in Game-Theoretic Modeling and Analysis. Econometric Society Monograph Series, no. 18. Cambridge: Cambridge Univ. Press, 1990.

Roth, Alvin E., and Xing, Xiaolin. "Jumping the Gun: Imperfections and Institutions Related to the Timing of Market Transactions." A.E.R. 84 (September 1994): 992-1044.

Suen, Wing. "A Competitive Theory of Equilibrium and Disequilibrium Unravelling in Two-Sided Matching." Rand J. Econ. 31 (Spring 2000): 101-20. 